\title{
DEVELOPING AN AUTOMATED STUDENT ACADEMIC RECORD MANAGEMENT WITH BUSINESS INTELLIGENCE APPROACH
}

\author{
Maria Dara C. Saquin ${ }^{1}$ \\ darasaquin@dmc.edu.ph
}

\author{
Dave E. Marcial ${ }^{2}$ \\ demarcial@su.edu.ph
}

\begin{abstract}
Student academic records management and assessment are among the vital processes in any higher education institution. These processes must be efficient and systematic. The significant problems of the current system that is holding the student's academic record have been observed and identified. Based upon the limitations and the challenges on the existing procedures of a manual storing and archiving of the students' academic records, a centralized students' academic record management system was proposed. This project primarily aimed to develop a computerized student academic record management system in order to help DMC College Foundation Incorporated (DMCCFI) Philippines improve its performance in the registrar services, specifically in the assessment and evaluation of student records. The newly developed system is integrated with business intelligence. It offers modules such as grade submission, assessment, and student kiosk with security feature. The development model included Rapid Application Development (RAD). The tools used in the development are Windows Server 2008 R2, DevExpress, Microsoft Visual Studio C\#, MSSQL, and SmartDraw. Based on the system evaluation, the proposed system is very good with an aggregate mean of 4.55. The result implies that the MIS staff, coordinators and dean strongly agree that the proposed system is highly acceptable. In terms of usability, the proposed system is rated with an aggregate mean of 6.43 described as "Strongly Agree." It was concluded that the developed system offers the capabilities and functions that can help improve the performance of the registrar services in DMCCFI and is highly recommended for immediate utilization by DMCCFI.
\end{abstract}

Keywords: Business Intelligence, Information System, Management Information Systems, Student Assessment, Student Self-Assessment, Student Kiosk

\section{Introduction}

Student academic records refer to the information that relates to a student's admission and academic performance in a college or a university. These records include the information that is contained in an original transcript, in electronically stored records, and in the official student academic record, as it is maintained by the office of the school registrar. An education record contains information directly related to a student; this means that the record is personally identifiable with and is maintained in various types of medium including handwritten or printed documents, microfilm/fiche, a computer's main memory, magnetic tape, cassette, and disk or diskette. These records are used to assist offices in support of basic institutional objectives and to document every student's progress and achievement in the academic aspect within the institution.

Records management is defined as a "field of management responsible for the efficient and systematic control of the creation, receipt, maintenance, use, and disposition of records, including the processes for capturing and maintaining evidence of and information about business activities and transactions in the form of records". The creation, maintenance, retention, and disposition of academic information are at the core of students' functions in higher educational institutions. Student records identify the academic institution's official student body, document their progress through a course of study, show degrees and

\footnotetext{
${ }^{1}$ College of Computer Studies, DMC College Dipolog City, Zamboanga del Norte

${ }^{2}$ College of Computer Studies, Silliman University, Dumaguete City, Negros Oriental
} 
certifications obtained, support applications for other institutions and support job applications, and are frequently referenced to as historical records. Student records and record keeping support document all the administrative activities related to the admission, attendance, advising and counseling of students, completion of coursework and requirements, graduation, and the attainment of a degree.

One of the best methods in student record administration is the "Automated Student Records System". Student records system is a professional and academic discipline concerned with the strategic, managerial, and operational activities involved in gathering, processing, storing, distributing, use of information and its associated technologies in society and organizations. Specifically, this computer-based record system is a complementary infrastructure of hardware and software that people or organizations use to collect, filter, process, create, and distribute data. Records systems are implemented within an organization for the purpose of improving the effectiveness and efficiency of that organization. The capabilities of the information system and characteristics of the organization, its work systems, the people, and its development and implementation methodologies collectively determine the extent to which that purpose is achieved.

In the United States, the University of Wisconsin-Madison has been using an automated academic record management system to ensure that the student academic records at that university meet the established record keeping requirements, protect the university's liability, provide institutional accountability, and safely guard the academic interests of students. In the Philippines, the University of the Philippines-Mindanao, University of the East-Manila Campus, University of San Carlos, Mindanao State University-Iligan Institute of Technology, Silliman University, and Holy Name University are among the few universities in the country that are already using the automated academic record management system.

On the other hand, the DMC College Foundation Inc. (DMCCFI) is among the many colleges in the Philippines that still implements the manual storage of student academic records. DMCCFI utilizes manual submission of grades using paper and manual student subject assignment. The manual submission of grades is done through the submission of a hard copy of the students' grades by the instructor. It is then signed by the Coordinator, the Dean of the school or college, the Dean of Instruction and the Vice President for Academic Affairs. Additionally, the process of the manual student subject assessment involves the coordinator to look through the student's submitted credentials. Based on what the coordinator sees appropriate, he or she will assign the possible subjects that will be taken by the student for the upcoming semester.

Further, business intelligence (BI) is a general term that refers to the overall capabilities a company uses to collect and analyze data from a variety of sources to better understand its operations and make better managerial decisions. BI technologies provided historical, current, and predictive views of business operations; BI applications also provide employees and top management with information at whatever time they need it, so they can make faster and better decisions. These systems allow a company to gather, store, access, and analyze corporate data that aid in the decision-making process. BI impacts in the areas such as customer profiling, customer support, market research, market segmentation, product profitability, statistical analyses, and inventory and distribution analyses.

To maintain a competitive edge, companies today are increasingly turning to operational business intelligence solutions that support process optimization. This entails pushing needed data to frontline analysts and managers in real time, thus supporting intraday decisions. This can dramatically improve efficiencies and decision-making across all facets of an enterprise. This paper presents the development of an automated student academic record management for DMCCFI. Specifically, this paper presents the analysis, design and implementation of the proposed system with emphasis on the integration of business intelligence as a tool for decision-making. 


\section{System analysis}

\subsection{The Current System}

The school's Registrar's Office keeps the academic records of all students from the academic units of DMCCFI. The process of submission of the final grades involves the following steps: First, the faculty member will submit the records to the coordinators for approval. Second, the coordinator will approve/disapprove the submitted grades. Third, the coordinator forwards the approved final grades to the dean for further approval. Fourth, the dean then forwards the grades to the dean of instruction for another approval. Fifth, the Dean of Instruction forwards the grades to the VP Academic Affairs for further approval and sixth, the Vice President for Academic Affairs then forwards the grades to the School Registrar for record keeping purposes.

Based upon the interview that has been conducted by the researcher, it was found that the registrar's office still implements the manual storage, sharing and issuance of Transcript of Records (TOR). For instance, the student who will request for his or her TOR will have to wait for at least three weeks or 15 working days for the processing. The person in-charge will manually retrieve the grades of the student through the utilization of Microsoft Excel. Upon admission to DMCCFI, a sheet in Excel is prepared for every student. This sheet contains a student's completed subjects and grades for the whole period that he or she is enrolled in the institution. The grades are then verified if it is correct by looking through the students' individual envelope. This envelope contains all the documents that are related to the students' transactions that he or she made with the registrar's office (e.g. student profile, enrollment forms, adding and dropping forms, and change grade forms). If the person in-charge finds the grades correct, these grades are retrieved and copied to the DMCCFI's transcript of records (TOR) template to be prepared for printing. If no error is found, the TOR is printed.

\subsection{Problems Encountered}

The problems encountered in the different departments and Registrar's of DMCCFI are the following:

Lack of needed information. For instance, in assessing student subjects, not all grades and student information are readily available for the coordinators to utilize in assessing the student. Some information and grades are in the registrar's office and are not shared with the departments; the coordinators will still have to get the records directly from the registrar. An estimate of 1 out of every 2 records of the students, who happened to be transferees, are not shared with the departments.

The manual system produces inaccurate results. For example, there were instances when discrepancies in the students' grades are apparently evident. This can be observed with the incongruence of the recorded grades by the registrar with that of the individual departments. About 1 out of every 10 students will request for a change of grade. This is the primary cause of mismatch between the records of the registrar and that of the departments.

The manual system approval of grades can cause excessive processing delays. For instance, when an instructor submits grades, it will take at least five days before it will be approved by the different offices. Such is the case because of the manual routing of the student grades.

\subsection{Functional Requirements}

A program's functional requirement describes what a software system should do entirely from the user's perspective; it also covers the description of the behavior of the system as it relates to the system's functionality. The functional requirements were formulated through the use of a prototype, especially in eliciting the requirements. A working prototype was developed to strategically capture the requirements that the coordinators and deans of DMCCFI have discussed with the researcher. The functionalities mentioned were based on existing standard requirements of the grade submission and assessment system, with the approval and coordination from DMCCFI coordinators and deans. They are as follows: 
FREQ 1: The instructors should be able to manage their grades.

FREQ 2: The instructors should know the status of their submitted grades, whether these have already been approved or not.

FREQ 3: The system should allow the coordinators/vice-deans/deans/dean of instructions and VPAA to approve grades.

FREQ 4: The coordinators, vice-deans, deans, dean of instructions and Vice President for Academic Affairs should be able to view the student's grade.

FREQ 5: The students should be able to view their grades.

FREQ 6: The system should allow the registrar staff to manage course prospectus.

FREQ 7: The coordinators should be able to assess the student subjects.

FREQ 8: The system should allow the coordinator to add, remove and force add subjects that are included in the proposed list.

FREQ 9: The students should be able to make self-assessment.

FREQ 10: The system should be able to provide the statistical reports for the decision support of the coordinators and deans.

FREQ 11: The system should be able to provide the standard reports for the students who failed based on a particular subject.

FREQ 12: The access to the system must be password protected.

FREQ 13: The access to the system should be prohibited if the number of re-tries exceeded the pre-set number.

\subsection{Non-Functional Requirements}

Non-functional requirements are constraints on the services and functions of the program and also expectations about performance. They can include target platform specifications, timing constraints, performance requirements, memory usage requirements, file access privileges, security requirements, response times, minimum number of transactions per second, and so on. These are usually requirements that may not be visible to the user, but which do affect the user experience. This should be contrasted with functional requirements that define specific behavior or functions. These requirements include a) The system shall ensure that data is protected from unauthorized access; b) The system shall be developed for Windows platforms.

\section{System scope}

This project is a LAN-based desktop application and is primarily focused on the automation and computerization of student academic records activities in all academic units of DMCCFI. Specifically, it focused on the development of the proposed system that covered only the following processes:

Module for Grade Submission. This included the submission and approval of final grades that came from the different departments; the routing and approval of grades will be from the instructor, to the coordinator, to the dean, to the dean of instruction, to the VP Academic Affairs, and lastly to the School Registrar; the processing and approval of change grade request from the students and instructor.

Module for Assessment. The system provided a tool that is designed to facilitate student mentoring and advising. It is a comprehensive and integrated set of evaluation measures that provides information for use in monitoring student performance. This emulated the process of student assessment by the coordinators. Proposed subjects were the output of this particular module. It provided a list of possible subjects that a student can enroll in a semester that is based on the curriculum. It also ranked the possible subjects to be taken by the student based on subject prioritization.

Module for Student Kiosk. Student Kiosk is a computer terminal containing a specialized software application that provides access to information for the students. This module provided the students with an interface to enable them to view their grades in currently enrolled subjects and for their own self-assessment. There is an already existing computer kiosk that is located inside the registrar's office that the students can freely use. 
Therefore, the development was only limited to the module for students' grades and selfassessment.

Security Module. This function provided administrative tools for system maintenance, facilitated management of look-up tables, system configuration, scheduled services, facilitated management of users and groups, and privileges and security.

Business Intelligence Integration. The system integrated business intelligence specifically in the query and reporting component. All the reports are dynamic, and update in real time if there are any transactions to be done by the users. Each report is generated by joining more than one table in the connectivity of database. This ensures the accuracy and consistency of the data in the report. The system provided enterprise reporting to serve the strategic management of DMCCFI. It only involved data visualization like statistical and graphical reporting technique. It offered customizable reports ready for printing in tabular and graphical format. In addition, it generated statistical reports of transactions such as students' grades per semester, provided a list of students who failed in a particular teacher or subject, and produced a list of students who need counseling and tutorials due to failing grades. It has business intelligence capabilities that help the Deans, Coordinataors etc. in assessing the failing/passing trends of a particular subject or instructor and to take better insight on these information. Moreover, it facilitated the generation of a faculty list at the end of each semester for those who failed or passed in their subjects As well as it provided customizable reports for the students TOR ready for printing.

This study is only limited to the standard operations and procedures in the submission of grades, automation of the student academic records and student course and subject assessment. Users of the system are also limited to the students, deans, coordinators, faculty members, and non-academic employees who comprise the registrar staff of DMC College Foundation. The computation of grades was not covered in this proposed system. The development of the proposed system also included a module for subject assessment, considering the absence of the said module in the presently-used enrollment system.

\section{Related systems}

There are related open-source systems that are most relevant to the proposed automated student record management system. Although it is open and free, customization of the system would be difficult considering that DMCCFI operates uniquely. Among these related systems are the following: Fedena, Pillmex, Scholl ERP, openSIS, and SchoolTool.

Fedena is multi-purpose school management software used by thousands of educational institutions worldwide for all administration, management, and learning-related activities. Moreover, Fedena is an open source school management software developed by Ruby on Rails framework. It is a web 2.0 application that is being developed by Foradian Technologies. Fedena is used by the Education Department of the Government of Kerala to automate the system and process over 15,000 schools in the state and later named as Sampoorna.

Pillarex School ERP has been designed to ensure data maintenance is made simpler and easier. Various user-friendly interfaces are featured to catalyze the process of reducing maintenance time, but the strong foundation of ERP data structure ensured the reliability and completeness of the data. Pillarex School Management software provides enhanced power to every single stakeholder of the school. Especially designed ERP is capable of managing different kinds of exceptions occurring in day to day transactions within the confines of different schools. Centralized system and standardized processes help in bringing uniformity to the school's system. Constant monitoring of reports leading to a realization of gaps and attempts at process re-engineering can lead to the betterment of the school.

The system called openSIS is one of several free and open source student information systems available for the K-12 curriculum and for higher education institutions. The solution was on the verge of development for several years, appearing to possess the functionality that long time commercial versions also have today. This kind of solution is a $100 \%$ web-based application, has a polished look, a great deal of required functionality and appears to be userfriendly as can be observed on its online demo website. The system is developed and 
maintained by Open Solutions for Education; it is written in the PHP programming language and uses the MySQL database system to store information.

SchoolTool is a GPL licensed, free student information system for schools around the world. The goals of this project are to create a simple turnkey student information system that includes demographics, grade book, attendance, calendaring, and reporting for primary and secondary schools. It has a framework for building customized applications and configurations for individual schools or states. SchoolTool is built as a free software/open source software stack licensed under the GNU General Public License, Version 2, written in Python using the Zope 3 framework.

In the same way, the budget preparation and monitoring system by Genove (2011) is integrated with business intelligence particularly in the query and reporting section [6]. All the reports are dynamic, and automatically updates in real time, should there be any transactions done by the system users. Most companies collect a large amount of data from their business operations. To keep track of that information, a business would need to use a wide range of software programs, such as Microsoft Excel, Access, and other different database applications that cater to various departments throughout their organization [7]. Using multiple software programs made it difficult to retrieve information in a timely manner and to perform analysis of the data. Business intelligence software like Sybase Business Intelligence Software Solutions, provided radically innovative enterprise analytics and data warehousing software tools that gave customers the power and speed they need to make actionable business intelligence a reality even in real time.

\section{The System Development}

\subsection{Functional Requirements}

A program's functional requirement describes what a software system should do entirely from the user's perspective; it also covers the description of the behavior of the system as it relates to the system's functionality [9]. The functional requirements were formulated through the use of a prototype, especially in eliciting the requirements. A working prototype was developed to strategically capture the requirements that the coordinators and deans of DMCCFI have discussed with the researchers. The functionalities mentioned were based on existing standard requirements of the grade submission and assessment system, with the approval and coordination from DMCCFI coordinators and deans.

\subsection{Non-Functional Requirements}

Non-functional requirements are constraints on the services and functions of the program and also expectations about performance. They can include target platform specifications, timing constraints, performance requirements, memory usage requirements, file access privileges, security requirements, response times, minimum number of transactions per second, and so on. These are usually requirements that may not be visible to the user, but which do affect the user experience [9]. This should be contrasted with functional requirements that define specific behavior or functions. 


\subsection{Conceptual Framework}

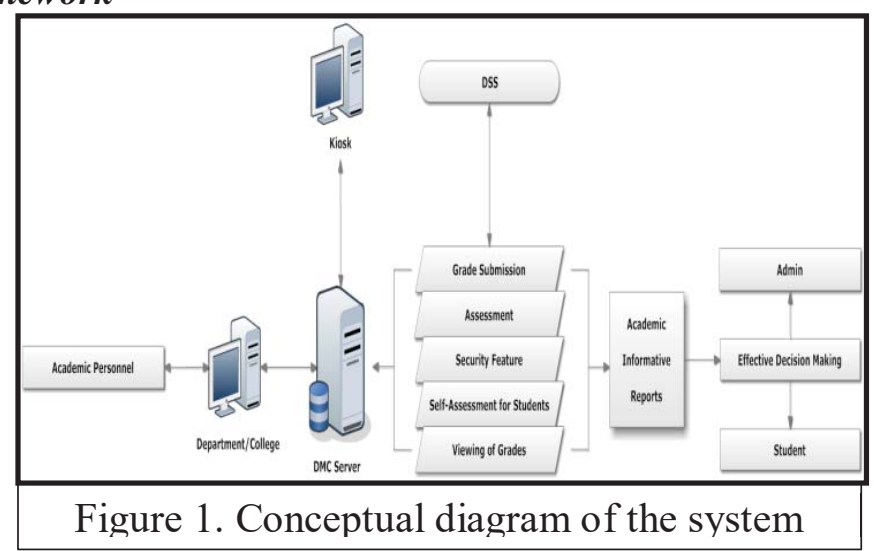

The model of the study follows the principle of input process-output-outcomes (Figure 1). The inputs are came from the faculty, students, non-academic personnel, coordinator, administrators, and deans in the different departments and offices of the school. The College of Nursing, College of Computer Studies, School of Hotel and Institution Management, School of Business Administration, Allied Health Sciences, School of Teacher Education, School of Criminology and the Registrar's Office were the primary concern of this study. The processes included the grade submission, student course and subject assessment by the coordinator, self-assessment by the students, administration and accessing, and viewing of students' records. The output provided decision support to faculty, deans, vice deans, coordinators and DMC Administrators.

\subsection{Development Models}

The following models were the bases during the analysis and design phase of the study:

Client-Server Architecture. In order to achieve the networking mechanism, the client server architecture was advised. A network architecture is used to service a single company, using a local area network (LAN), or sometimes a wide area network (WAN), where many, many client computers communicate with a single server computer. The server computer, quite literally, serves up information and services. The client computer consumes information provided by the server computer. There is a two-way interaction between the client computer and the server computer, such that client computers can also send information back to server computers. The Client-Server model of computing was a distributed application structure that partitioned tasks or workloads between the providers of a resource or service, called servers, and service requesters, called clients. Often, clients and servers communicated over a computer network on separate hardware, but both client and server may reside in the system.

Unified Modeling Language (UML). Unified Modeling Language (UML) is a collection of languages that primarily supports object-oriented modeling of software systems in terms of flows, objects, and messages [10]. The UML is a tool for specifying software systems. Standardized diagram types help to describe and visually map a software system's design and structure. It is possible to model just about any kind of application, both specifically and independently of a target platform through the use of UML.

Enterprise Reporting. Enterprise reporting or production reporting typically involves high-volume, high-resolution reports that are run on a regular basis. It was used as the regular provision of information to decision-makers within an organization to support them in their work (dangling). These reports can take the form of graphs, text and tables and are typically disseminated through an intranet as a set of regularly updated web pages (or enterprise portal). Alternatively, they may be e-mailed directly to users or simply printed out and handed around, in a time-honored fashion.

Data Visualization. Data visualization is the study that visually presents abstracted information in certain schematic forms, which also includes their own attributes and variables. The basic aim of the data visualization is to convey the information with graphical 
methods in a more clear and effective way. The main goal of data visualization is to communicate information clearly and effectively through graphical means. It does not mean that data visualization needs to look boring to be functional or extremely sophisticated to look beautiful.

\subsection{Development Tools}

The following are the tools that were used in the development of the proposed system of DMC College Foundation:

Windows Server 2008 R2 -It was used to host the proposed system.

Microsoft SQL Server 2008 - It was used in the connectivity of databases in the programming application of the proposed system.

Microsoft Visual Studio - an integrated development environment (IDE) from Microsoft. It was used to develop console and graphical user interface applications.

C\# - the language that was used for the development of the automation of the preparation and submission of the students' grades and assessment which uses Microsoft Visual Studio as the integrated development environment (IDE).

DevExpress - a customization tool to help enhance the forms and reports. This was also used for data visualization. For the integration of business intelligence, enterprise reporting and data visualization were used together with the customization tool-DevExpress.

Smart Draw - a visual processor used to create flowcharts, organization charts, mind maps, project charts, and other visuals. This was the tool that was used to create graph, charts and processes in the proposed system.

\section{The System}

A user-interface is a set of commands or menus through which a user communicates with a program. Screen layout is one of the many attributes of the system when it comes to its user-friendliness. It should be designed in such a way that the users can navigate through the system quickly and easily. It should also provide a clear recognition of the task that users need to perform. The DMC Automated Student Record Management and Assessment screen layout (Figure 2), shows the main menu and icons in the system. It would be used for grade submission, assessing students, adding prospectus and subjects, viewing of grades and currently enrolled subjects. The processing is done by the instructors, the coordinators, and the deans. The registrar is tasked to handle the processing, and provide services to the patrons.

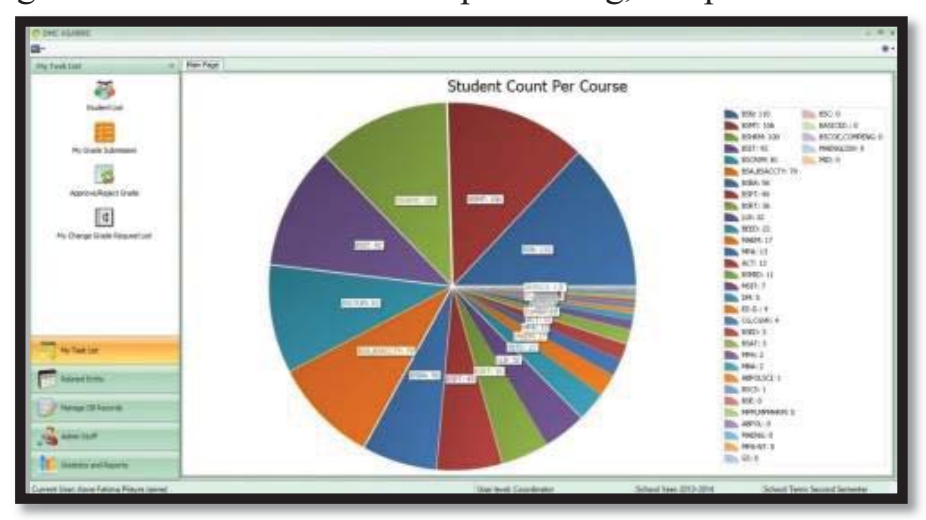

Figure 2. Main Menu of the Automated Student Academic Record Management and Assessment. 


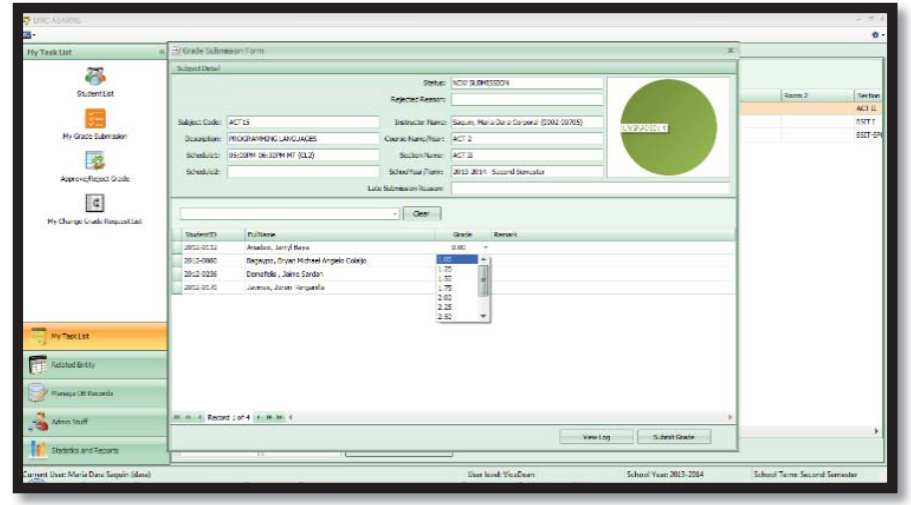

Figure 3. Module for Grade Submission

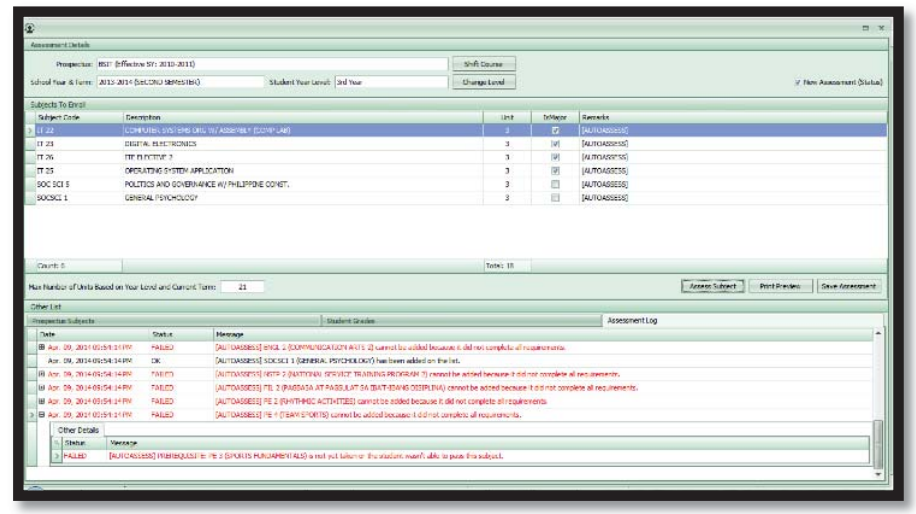

Figure 4. Module for Assessment.

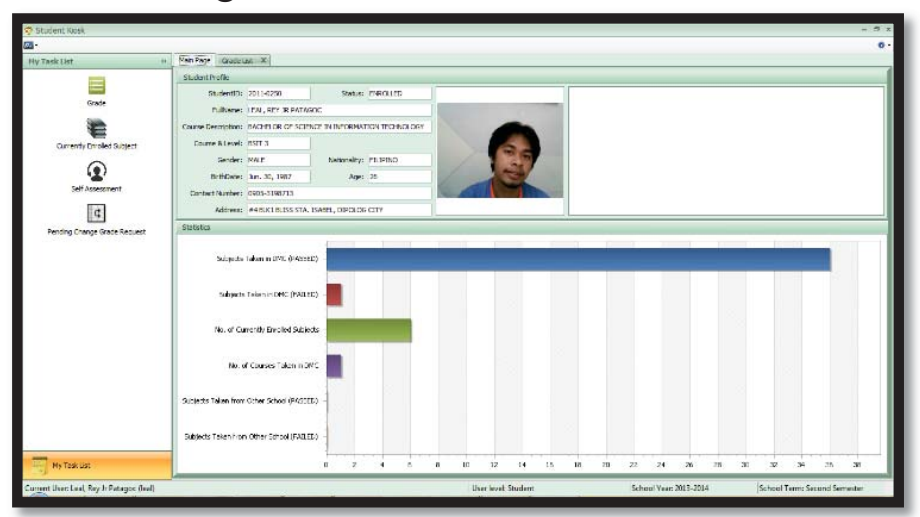

Figure 5. Module for Student Kiosk.

\section{Business Intelligence Integration}

As used in this study, the term Business intelligence (BI) refers to the overall capabilities a company uses to collect and analyze data from a variety of sources to better understand its operations and make better managerial decisions [4]. Business intelligence means the ability of an organization to collect, maintain, and organize knowledge. It aims to support better business techniques and decision-making ability with solutions that take business intelligence (BI) to a whole new level in getting the right information. The system used enterprise reporting, particularly the tabular type of business intelligence reporting. The system integrated business intelligence specifically in the query and reporting component. All the reports are dynamic, and update in real time if there are any transactions to be done by the users. Each report is generated by joining more than one table in the connectivity of database. This ensures the accuracy and consistency of the data in the report.

In this system, the queries and computations are both done in stored procedure in Microsoft SQL Server 2008 and DevExpress report feature. There are several reports created for the department heads (coordinators, deans and vice deans). These reports are generated 
within a specific semester and school year. Figure 7 presents the comprehensive graphical representation of the semestral student passing percentage by instructor. Figure 7 presents the comprehensive graphical representation of the student passing percentage by subject for every semester. Figure 8 presents a detailed summary of the students who passed and failed in a particular subject. Figure 9 presents the students QPA by course.

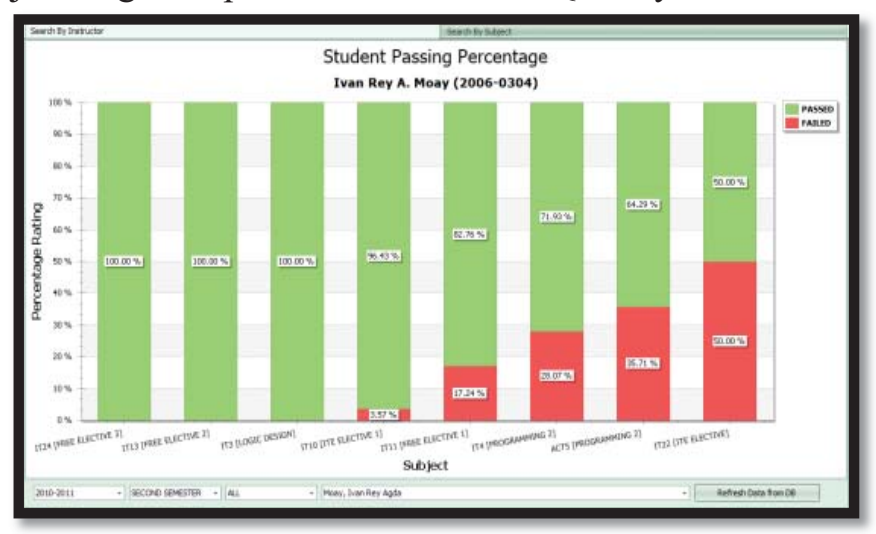

Figure 6. Screenshot of Student Semestral Passing Percentage Graph by Instructor

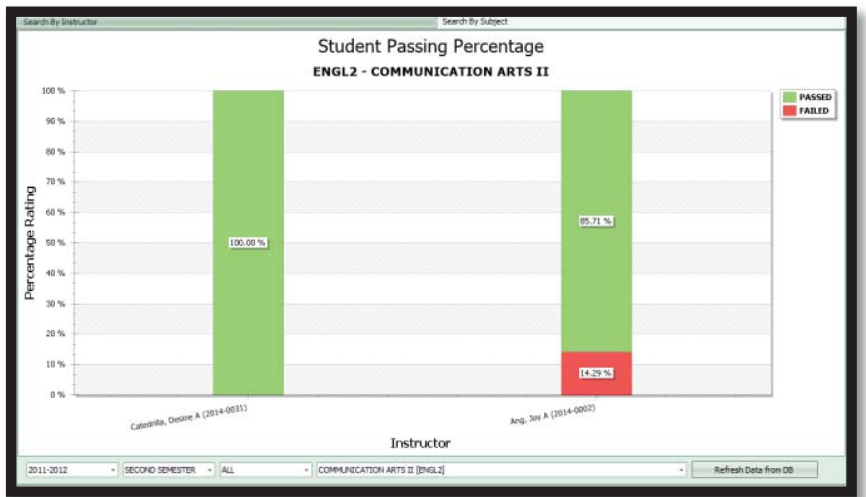

Figure 7. Screenshot on the student passing percentage by Subject

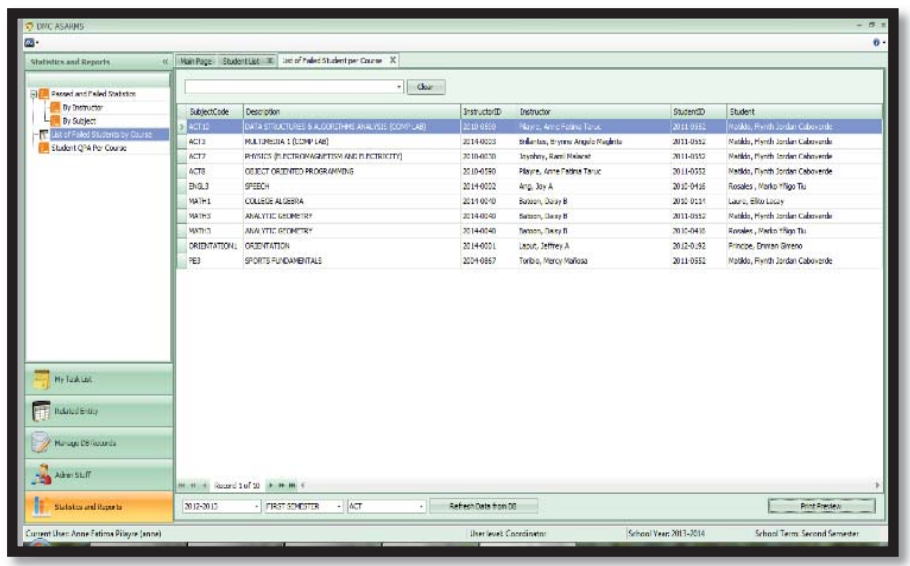

Figure 8 . Screenshot of the list of students who failed by course. 


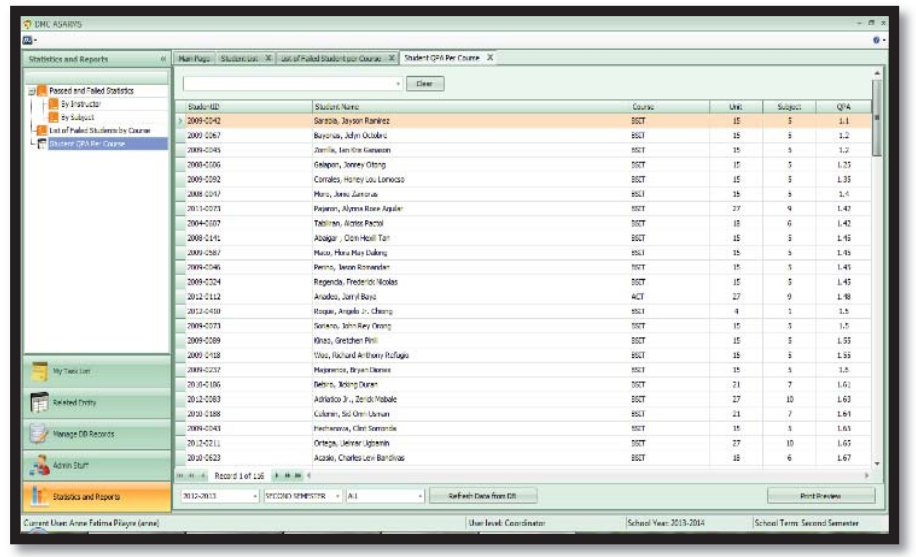

Figure 9. Screenshot of the student QPA by course.

\section{System Evaluation}

The system usability test was conducted by the researchers in seven departments/colleges, namely: College of Nursing, School of Criminology, Allied Health Sciences, College of Computer Studies, School of Education, School of Business Administration and School of Hotel Restaurant and Institution Management from February $13-22,2014$. A summary of the distribution of the respondents shows that of the 271, 243 are DMCCFI students, 24 are DMCCFI faculty, and four are DMCCFI coordinators and department heads. The IBM Computer Usability Satisfaction Questionnaire by Lewis (2009) was the evaluation tool used.

For the computer system usability testing, These were completed by the faculty, coordinator, dean, dean of instruction, VPAA, registrar, registrar staff, secretary, and some selected students to make sure that the system conformed to their needs and requirements. After each testing, an evaluation form was provided for testers in order to rate the responsiveness, accuracy, and efficiency of the system. The evaluation form consisted of criteria with relevance to the system. The gathered data were compared and were assessed in accordance with the projects' objectives. It was also scaled to check if the system satisfies the requirements. The comments and suggestions from the users were also gathered for the purpose of further improvement of the system.

During the actual survey administration of the college students of DMCCFI, a random selection procedure was utilized. There were two different groups for the administration. The first group, DMCCFI students $(n=243)$ (Table 2), were randomly selected during computer laboratory classes for the reason that the demonstration has to be conducted inside the computer laboratory. The researchers asked for an approval from the dean of instruction and the instructors in-charge in the laboratory room before the demonstration and testing process. Some faculty, laboratory assistants and student assistants helped in the conduct of the system usability evaluation. The researchers demonstrated the system's features in detail, viewing of currently enrolled subjects, status of change grade request, and student self-assessment modules. The respondents also did some hands-on self-assessment processes. After the hands-on, they answered the same system usability questionnaire.

The second group of system usability testing was also conducted by the researchers in Computer Laboratory 3 and the respondent's offices, in order to consider the evaluation coming from the faculty, coordinators and department heads. This group of respondents did some hands-on on grade submission, grades approval, adding prospectus, adding subjects on prospectus, student assessment processes. The researchers asked an approval from the Vice President for Academic Affairs, Dean of Instruction and College Deans before the demonstration and testing process. During the demonstration, the automated grade submission and assessment features were presented in detail. The respondents were asked to answer the system usability survey questionnaire. A total of 28 respondents of this group participated during the system usability evaluation, wherein 24 were DMCCFI faculty while 4 were coordinators. 
System usability results from the students, faculty and coordinators were computed through their average weighted mean. According to the students, the average weighted mean of the system usability is 6.4 with the interpretation of "Strongly Agree". According to the faculty, the average weighted mean of the system usability is 6.5 with the interpretation of "Strongly Agree". According to the coordinators, the average weighted mean of the system usability is 6.4 with the interpretation of "Strongly Agree". This implies that the system is strongly high in its usability. This result also suggests that the system provides high satisfaction among the respondents. Likewise it reveals that the system is highly simple and easy to use, effective, efficient, informative, easy to understand, and clear. Further, this implies that majority of the respondents strongly agree with the capabilities, functions, and the ease of use of the proposed system.

\section{Conclusion}

After a thorough analysis of the problem and design, the proposed automated student academic record management and assessment of DMCCFI was successfully developed. The system is usable and acceptable by the users as manisfested in the usability and acceptance testing. However, there is a need to improve the performance of the manual system specifically on the need to improve response time of the processes. There is also a need to improve the manual records management that would provide accurate information and without capturing the information redundantly. In the same manner, there is also a need to improve the control and security measures of the manual records management and assessment of DMCCFI. Moreover, there is a need to improve the registrar's manual services to its clientele. Further, problems and challenges of the DMCCFI records management and assessment services are recurring because of the manual operations that can cause delay in the processes.

The proposed system can improve the performance, control and security of the registrar's services. The proposed system is efficient, effective, and user-friendly. It is very good in terms of usability and accessibility. The faculty member, coordinators, and students believe and are confident that the system is very usable. The developed system has functions and features that are highly-acceptable by the users such as grade submission, assessment, student kiosk, and security feature/administration. It offers graphical enterprise reporting as business intelligence technique for decision-support. Furthermore, the proposed system enables the coordinators and department heads to maintain and organize grade submission processes and student assessment for better decision-making.

\section{Recommendations}

Based on the aforementioned conclusions, it is highly recommended that the proposed system should implemented in DMC College Foundation. For a successful implementation of the proposed system, the following recommendations should be considered:

An administrative policy has to be formulated that will include a rigid system orientation, user awareness and updates in the automated record management and assessment of the institution;

An intensive hands-on training for the prospective users in order to build awareness of the system's capabilities and features;

A parallel run for the implementation of the system, to be conducted in time for 1st semester, the results of which will be compared to the manual process of the grade submission and student assessment;

Maintain optimal functioning conditions of the server and create maintenance plan needed to ensure the system usability that are constantly delivering effective and efficiency of the system;

The developer, together with all the coordinators and department heads of DMCCFI should conduct an evaluation of the system per semester for further improvement and development; and, 
The administration should add a policy regarding INC (for students who only have incomplete requirements in a subject or for students who may be considered to pass the subject through removal exams) instead of giving the student an automatic mark of 5.0, which is mandated under CHED Memorandum Order 2 series of 2010.

\section{Acknowledgments}

We would like to give thanks to the Commission on Higher Education (CHED) for the Faculty Development Program Scholarship and DMC College Foundation for the endorsement of the Scholarship. Our invaluable gratitude to Dr. Reynaldo Rivera, Engr. Chuchi S. Montenegro, Dr. Yong Gyun Kim and Mr. Mark Onte for their guidance and for rendering their professional opinion. We would like also to acknowledge the inputs during the 12th National Conference in Information Technology Education (NCITE 2014) on October 23 - 25, 2014, Boracay, Aklan, Philippines.

\section{REFERENCES}

Definition of Student Academic Records. (2013). Retrieved from Undergraduate Medical Education University of Toronto website,

http://www.md.utoronto.ca/students/acad_prof/Student_Academic_Records/Definition_of_Student_Aca demic_Records.htm

Records Management Overview - Records Management (2013), Retrieved from UW - Madison Libraries websitet http://archives.library.wisc.edu/records/Overview.html

Quible, Z. (2004). An Introduction to Administrative Office Management:The Organizing Process

Dubai Computer Services (2013), Retrieved from Malumat ${ }^{\mathrm{TM}}$ Business Intelligence Systems website http://dubai-computer-services.com/business_intelligence.html

Runcie, T., and Mark D. (2013). Making Effective Business Decisions Using Microsoft Project. John Wiley \& Sons: Business Intelligence: Knowledge of Key Success Ingredients for Project Server

Genove, P. G. and Marcial, D. E. (2012). Network-driven Budget Preparation and Monitoring System. Presented during the 10th National Conference on IT Education on October 18-20, 2012 at Northwestern University, Laoag City, Ilocos Norte.

SYBASE (August 19, 2011), Business Intelligence \& Analytics, Retrieved from http://www.sybase.com/products/datawarehousing/business-intelligence

Dooley, J. (2011). Software Development and Professional Practice. Object Oriented Design Principles.

Rittgen, P. (2007). Enterprise Modeling and Computing with UML. IGI Global. Data Modelling Design.

Runcie, T., and Mark D. (2013). Making Effective Business Decisions Using Microsoft Project. John Wiley \& Sons: Organizational Structures

Banu Inanc Uyan Dur, Analysis of Data Visualizations in Daily Newspapers in Terms of Graphic Design, Procedia - Social and Behavioral Sciences, Volume 51, 2012, Pages 278-283, ISSN 1877-0428 